\title{
Gestational weight gain and its effect on fetomaternal outcome
}

\author{
Khushboo Singh ${ }^{1 *}$, Alka Goel ${ }^{1}$, Anupriya Narain ${ }^{2}$
}

\begin{abstract}
${ }^{1}$ Department of Obstetrics and Gynaecology, ABVIMS and Dr Ram Manohar Lohia Hospital, New Delhi, India
${ }^{2}$ Department of Obstetrics and Gynaecology, MAMC and associated Lok Nayak Hospital, New Delhi, India
\end{abstract}

Received: 07 August 2020

Revised: 19 September 2020

Accepted: 21 September 2020

\author{
*Correspondence: \\ Dr. Khushboo Singh, \\ E-mail: doc.khushboosingh@gmail.com
}

Copyright: () the author(s), publisher and licensee Medip Academy. This is an open-access article distributed under the terms of the Creative Commons Attribution Non-Commercial License, which permits unrestricted non-commercial use, distribution, and reproduction in any medium, provided the original work is properly cited.

\begin{abstract}
Background: In normal pregnancy, variable amount of weight gain is a constant phenomenon. The study aims to find an association between gestational weight gain and fetomaternal outcome. GWG (using institute of medicines guidelines meant for US population) and pregnancy outcomes among Asian Indians across different BMI categories (according to WHO Asia Pacific BMI cut points) were studied.

Methods: 300 women were split into the three groups based on their gestational weight gain. Namely, below recommended GWG, recommended GWG and above recommended GWG group. Comparison of various fetomaternal outcomes was done between these groups.

Results: In women, who had higher than recommended GWG, 30.5\% developed GDM, 23.2\% had gestational hypertensive disorder, 36.6\% developed hypothyroidism, $12.2 \%$ had pre-term birth and $15.9 \%$ had low birth weight. In recommended GWG category, these were 5.4\%, 4.5\%, 30.6\%, 7.2\% and $17.1 \%$ respectively; and in below recommended category, these were $14 \%, 1.9 \%, 22.4 \%, 12.1 \%$ and $24.3 \%$ respectively.

Conclusions: GWG generally follows the BMI pattern at the time of entering into pregnancy, higher the BMI more the GWG. More GWG was associated with GDM, Gestational hypertensive disorders and poor APGAR at birth. Below recommended GWG was associated with higher occurrence of GDM. No statistical correlation, between GWG and mode of delivery, NICU stay, preterm birth and birth weight was observed. Larger study is required to establish the applicability of IOM Guidelines for GWG on Indian women.
\end{abstract}

Keywords: Gestational weight gain, Fetomaternal outcome, BMI

\section{INTRODUCTION}

In normal pregnancy, variable amount of weight gain is a constant phenomenon. The amount of weight gain during pregnancy can affect the immediate and future health of woman and her infant. Therefore, there should be an ideal weight gain during pregnancy to achieve a good pregnancy outcome. Ideal weight gain during pregnancy depends on prepregnancy BMI levels. In May 2009, the institute of medicine published a revision of its 1990 GWG recommendations (Table 1).

These guidelines are intended for use among women in United States and their applicability in Asian countries is not known. Just as different BMI criteria have been declared by WHO for Asian population, ideal GWG requirements are likely to be different for Asian women as compared to American women. Suggested WHO BMI cut-off values for Asian population are given in (Table $2) .^{2}$

Some recent studies from Asia have concluded that IOM guidelines are suitable for the Asian population, whereas others have reported that GWG among Asians is different from what has been recommended by the IOM..$^{3-6}$ There are very few studies from India that have looked at the applicability of the IOM guidelines in pregnant Indian women. Furthermore, there are no national guidelines for 
weight gain during pregnancy in India. The weight gain recommendations by the IOM are in turn, based on Western WHO BMI cutoffs, making it difficult to compare, translate, or generalize their findings to Asian Indians.

Table 1: Institute of medicine 2009 gestational weight gain guidelines. ${ }^{1}$

\begin{tabular}{|lll|}
\hline & $\begin{array}{l}\text { Total } \\
\text { weight } \\
\text { gain }\end{array}$ & $\begin{array}{l}\text { Incremental weight } \\
\text { gain during the } \\
\text { second and third } \\
\text { trimester }\end{array}$ \\
\hline $\begin{array}{l}\text { Preconception } \\
\text { BMI }\end{array}$ & $\begin{array}{l}\text { Range } \\
(\mathrm{Kg})\end{array}$ & $\begin{array}{l}\text { Mean (range) } \\
\text { (Kg/wk) }\end{array}$ \\
\hline $\begin{array}{l}\text { Underweight } \\
\left(<\mathbf{1 8 . 5} \mathbf{~ K g} / \mathbf{m}^{2}\right)\end{array}$ & $12.5-18$ & $0.51(0.44-0.58)$ \\
\hline $\begin{array}{l}\text { Normal weight } \\
\left(\mathbf{1 8 . 5}-\mathbf{2 4 . 9} \mathbf{~ K g} / \mathbf{m}^{2}\right)\end{array}$ & $11.5-16$ & $0.42(0.35-0.50)$ \\
\hline $\begin{array}{l}\text { Overweight } \\
\left(\mathbf{2 5 . 0 - 2 9 . 9} \mathbf{~ K g} / \mathbf{m}^{2}\right)\end{array}$ & $7-11.5$ & $0.28(0.23-0.33)$ \\
\hline $\begin{array}{l}\text { Obese } \\
\left(\mathbf{3 0 . 0} \mathbf{~ K g} / \mathbf{m}^{\mathbf{2}}\right)\end{array}$ & $5-9$ & $0.22(0.17-0.27)$ \\
\hline
\end{tabular}

Table 2: BMI range for Asian population as per WHO. ${ }^{2}$

\begin{tabular}{|ll|}
\hline Pre-pregnancy BMI $(\mathrm{Kg} / \mathrm{m} 2)$ & Category \\
\hline Less than 18.5 & Underweight \\
\hline $\mathbf{1 8 . 5}-22.9$ & Normal \\
\hline $\mathbf{2 3}-\mathbf{2 4 . 9}$ & Overweight \\
\hline More than 25 & Obese \\
\hline
\end{tabular}

We, therefore, aimed to compare the weight gain during pregnancy (using IOM weight gain guidelines) among Asian Indians across different BMI categories (using WHO Asia Pacific BMI cut points) and to compare the pregnancy outcomes in each of the different BMI categories.

\section{METHODS}

The study was a cross sectional observational study, conducted at the department of obstetrics and gynaecology, postgraduate institute of medical education and research (PGIMER), Dr. R.M.L. hospital, New Delhi over period of 1 year and 4 months from November 2017 to Mach 2019.

Three hundred pregnant women attending the hospital, either in antenatal clinic or ward admission, any time in pregnancy with documented prepregnancy weight or documented weight before 8 week period of gestation, were enrolled in the study after ruling out the exclusion criteria.

\section{Inclusion criteria}

Inclusion criteria for current study were patients with Singleton pregnancy and cephalic presentation.

\section{Exclusion criteria}

Exclusion criteria for current study were patients with multifetal pregnancy, presence or history of any medical disorders (chronic hypertension, pregestational diabetes, uncontrolled thyroid disorder, chronic renal disease, connective tissue disorders etc) and patients with major malformations in fetus.

After taking written and informed consent, detailed history and examination was done at the time of delivery or early in labour along with weight measurement. Presence of gestational diabetes mellitus and hypertensive disorders was noted along with any treatment history. Need for operative delivery, new born birth weight, gestational age and APGAR score at birth were recorded and the newborn was followed up for NICU stay before discharge. Three groups were made according to gestational weight gain for their respective BMI, namely, below recommended gestational weight gain (GWG), recommended GWG and above recommended GWG group. GWG recommendations according to IOM 2009 guideline were used on BMI recommendation for Asian population, as described in (Table 3) and fetomaternal outcomes were observed in these three groups. ${ }^{1}$ Statistical evaluation was performed by standard statistical methods.

Table 3: Three groups of study population. ${ }^{1}$

\begin{tabular}{|llll|}
\hline $\begin{array}{l}\text { BMI (WHO Asian cut } \\
\text { ofit) Kg/m2 }\end{array}$ & Below recommended GWG & Recommended GWG & Above recommended GWG \\
\hline $\begin{array}{l}\text { Underweight } \\
\text { (Less than 18.5) }\end{array}$ & $<12.5 \mathrm{Kg}$ & $12.5-18 \mathrm{Kg}$ & $>18 \mathrm{Kg}$ \\
\hline $\begin{array}{l}\text { Normal } \\
(18.5-22.9)\end{array}$ & $<11.5 \mathrm{Kg}$ & $11.5-16 \mathrm{Kg}$ & $>16 \mathrm{Kg}$ \\
\hline $\begin{array}{l}\text { Overweight } \\
(23-24.9)\end{array}$ & $<7 \mathrm{Kg}$ & $7-11.5 \mathrm{Kg}$ & $>11.5 \mathrm{Kg}$ \\
\hline $\begin{array}{l}\text { Obese } \\
\text { (more than 25) }\end{array}$ & $<5 \mathrm{Kg}$ & $5-9 \mathrm{Kg}$ & $>9 \mathrm{Kg}$ \\
\hline
\end{tabular}




\section{RESULTS}

Out of 300 cases, 22 were underweight, 164 were normal weight, 34 were overweight and 80 were obese at the time of starting pregnancy. $54.5 \%$ of underweight women gained below recommended weight, $36.4 \%$ had recommended weight gain and $9.1 \%$ had above recommended weight gain. $51.8 \%$ normal weight women gained less than recommended weight, $38.4 \%$ gained recommended weight and $9.8 \%$ gained above recommended weight. $60 \%$ women in obese group gained above recommended weight and $47.1 \%$ women in overweight group gained above recommended weight. $30.5 \%$ women who gained weight above recommendation developed GDM, while only $5.4 \%$ developed GDM in the recommended weight gain group and this difference was statistically significant, Chisquare value $=4.643, p=0.031$. The distribution of GDM was also higher in the below recommended GWG group $(14 \%)$ as compared to recommended GWG group, and the difference was statistically significant, Chi-square value $=22.007, \mathrm{p}<0.001$.

In this study, gestational hypertensive disorders were $1.9 \%$ in women with GWG below recommended, $4.5 \%$ in women with recommended gestational weight gain and $23.2 \%$ in women with above recommended GWG and this difference was statistically significant $(\mathrm{p}<0.001)$.
Rate of LSCS and operative vaginal delivery was compared between the three groups, no statistically significant difference was found.

Poor APGAR score of 6 and 7 at one minute was more frequent among babies of women with gestational weight gain above (2.8\%) as well as below (8.5\%) recommendation as compared to women with recommended $(0.9 \%)$ GWG group. This difference was statistically significant $(\mathrm{p}=0.014)$.

$23.4 \%$ babies of below recommended GWG group required NICU admission, $24.3 \%$ babies in recommended and $24.4 \%$ in above recommended GWG group required NICU admission. There was no statistically significant difference in NICU stay between different GWG groups. $12.1 \%$ babies in below recommended GWG group, $7.2 \%$ in recommended GWG and $12.2 \%$ in above recommended GWG group were preterm. However, the difference was not statistically significant.

Highest numbers of low birth weight babies (24.3\%) were of women with below recommended GWG as compared to $17.1 \%$ in recommended weight gain and $15.9 \%$ in above recommended GWG group. Only 2 babies in the total study population were macrocosmic and they were in above recommended GWG group. However, there was no statistically significant difference in low Birth weight between women with gestational weight gain below recommended, recommended and above recommended.

Table 4: Summary of results.

\begin{tabular}{|c|c|c|c|c|}
\hline & GWG & & & \\
\hline Study Area & $\begin{array}{l}\text { Above recommended } \\
(\%)\end{array}$ & $\begin{array}{l}\text { Recommend } \\
(\%)\end{array}$ & $\begin{array}{l}\text { Below recommended } \\
(\%)\end{array}$ & p value \\
\hline $\begin{array}{l}\text { Women who developed gestational } \\
\text { diabetes mellitus }\end{array}$ & 30.5 & 5.4 & 14 & $<0.001$ \\
\hline Gestational hypertensive disorder & 23.2 & 4.5 & 1.9 & $<0.001$ \\
\hline Mode of delivery (operative delivery) & 17.1 & 18.9 & 20.6 & 0.832 \\
\hline Pre-term birth & 12.2 & 7.2 & 12.1 & 0.395 \\
\hline Low birth weight & 15.9 & 17.1 & 24.3 & 0.261 \\
\hline Poor APGAR (6 and 7) & 2.8 & 0.9 & 8.5 & 0.014 \\
\hline NICU stay & 23.4 & 24.3 & 24.4 & 0.982 \\
\hline
\end{tabular}

\section{DISCUSSION}

In this study, pregnant women who were underweight at the time of starting pregnancy had tendency to gain less than recommended weight during pregnancy as compared to overweight and obese women. Likewise, women who were overweight or obese in pre-pregnant state, gained more than recommended weight during pregnancy as compared to underweight and normal weight women. This was consistent with the study by Heerman et al in their study in 2015, it was observed that, women who were overweight and obese had tendency to gained more than recommended weight during pregnancy. ${ }^{7}$
The number of women who developed GDM in present study was significantly higher in the two groups who gained less or more than recommended weight during pregnancy as compared to women with normal GWG. Thorsdottir et al, Brennand et al and Kieffer et al also reported that women whose GWG was below the recommended range had a higher likelihood of GDM. ${ }^{8,9,10}$ Li et al observed that overweight and obese women who had above recommendation GWG had 16 to 22 fold risk of GDM as compared to those with normal weight and recommended GWG. ${ }^{11}$

In the present study number of women with hypertensive disorders of pregnancy was higher in those who had 
above recommended GWG and least in those who had below recommended GWG. On analysis, association of hypertensive disorders of pregnancy with above recommended GWG was found to be statistically significant when compared with recommended GWG group ( $\mathrm{p}<0.001$; odds ratio 6.394). However, protective effect of below recommended GWG on development of hypertensive disorders of pregnancy could not be established statistically ( $\mathrm{p}=0.285$; odds radio 0.404 ). Larger studies are required to confirm any association between low weight gain in pregnancy and hypertensive disorders of pregnancy. Similar conclusion was drawn by Chasan et al who reported that those who gained weight above IOM guidelines had an odds ratio of 3.82 for hypertensive disorder. ${ }^{12} \mathrm{Li}$ et al also found similar outcome in their study that obese women who had excessive GWG showed almost 6 fold rise of pregnancy induced hypertension compared with women with Normal pre-pregnancy BMI and adequate GWG. ${ }^{13}$

$20.6 \%$ of women in below recommended GWG group had delivery by cesarean section, $18.9 \%$ of women in recommended GWG group and $17.1 \%$ women in above recommended GWG group had delivery by cesarean section. There was no statistically significant difference in mode of delivery between different study groups $(p=0.832)$. Indication for cesarean delivery like contracted pelvis, cephalopelvic disproportion, cesarean on demand, previous cesarean delivery were excluded in this study. Similarly, Hope Rosemarie Farquharson et al also found in their study in 2018 that there was no statistically significant relationship between GWG and mode of delivery. ${ }^{14}$

APGAR score at birth was compared in different study groups. Poor APGAR score i.e. APGAR score of 6 and 7 was more common in GWG above recommended group and this difference was statistically significant $(\mathrm{p}=0.014)$. Similarly, in a meta analysis in 2015 by Zhu et al it was found that excessive weight gain was associated with poor APGAR. ${ }^{15}$

72 out of 300 (24\%) babies required NICU admission. $23.4 \%$ of below recommended GWG group required NICU admission of their babies, $24.3 \%$ of recommended GWG group and $24.4 \%$ of above recommended GWG group babies required NICU admission. There was no statistically significant difference in need for NICU admission in different GWG groups. On the other hand, Kiymet et al found that the rate of the admission of new borns to the neonatal intensive care unit was significantly more in women with excessive GWG than in women with normal weight gain. ${ }^{16}$ On the contrary, Baugh et al in found that women who had less than recommended GWG were more likely to give birth to babies who required NICU admission just after birth. ${ }^{17}$ Thus, further large scale studies are required to establish association of GWG and NICU stay, if any.
Preterm birth were more in both above and below recommended GWG groups i.e. $12.2 \%$ and $12.1 \%$ respectively as compared to $7.2 \%$ in recommended GWG group. Although maximum number of preterm birth was in above recommended GWG group, the difference was statistically insignificant when the study groups were compared with each other $(\mathrm{p}=0.395)$. This result was in consonance with the study by Mozhgan et al in which no relationship between GWG and preterm delivery was observed. $^{18}$

58 out of $300(19.33 \%)$ babies were low birth weight, and 3 were macrocosmic in the study population. Out of 3 macrocosmic babies, two belonged to GWG above recommended group. Maximum percentage i.e. $24.3 \%$ babies in below recommended GWG group were low birth weight as compared to $17.1 \%$ in recommended GWG group and $15.9 \%$ in above recommended GWG group. But statistically there was no significant difference in distribution of low birth weight babies between different study groups. A larger study is required to establish whether correlation of GWG and birth weight is significant. Similar result was observed in a study on 12,561 women, by Baugh et al who found that women who gained less than recommended weight were more likely to give birth to low birth weight babies as compared to those who gained recommended weight or above recommended weight in pregnancy. ${ }^{17}$

\section{CONCLUSION}

GWG generally follows the BMI pattern at the time of entering into pregnancy, higher the BMI more the GWG. More GWG was associated with GDM, Gestational hypertensive disorders and poor APGAR at birth. Below recommended GWG was associated with higher occurrence of GDM. No statistical correlation, between GWG and mode of delivery, NICU stay, preterm birth and birth weight was observed. GWG above or below recommended level may be a modifiable risk factor to improve outcomes of pregnancy. Larger study is required to establish the applicability of IOM Guidelines for GWG on Indian women, protective effect of low GWG on gestational hypertensive disorders, association of GWG with birth weight and NICU stay.

\section{Funding: No funding sources \\ Conflict of interest: None declared}

Ethical approval: The study was approved by the Institutional Ethics Committee

\section{REFERENCES}

1. Simas TAM, Waring ME, Sullivan GMT, Liao X, Rosal MC, Hardy JR, et al Institute of medicine 2009 gestational weight gain guideline knowledge: survey of obstetrics/gynecology and family medicine residents of the United States. Birth. 2013;40:237-46.

2. The Asia-Pacific perspective: redefining obesity and its treatment, World Health Organization. Available 
at: https://apps.who.int/iris/handle/10665/206936. Accessed on 20 June 2020.

3. Yang YD, Yang HX. Investigation into the clinical suitability of institute of Medicine 2009 guidelines regarding weight gain during pregnancy for women with full term singleton fetus in China. Zhonghua $\mathrm{Fu}$ Chan Ke Za Zhi. 2012;47(9):646-50.

4. Liu Y, Dai W, Dai X, Li Z. Prepregnancy body mass index and gestational weight gain with the outcome of pregnancy: a 13-year study of 292,568 cases in China. Arch Gynecol Obstet. 2012;286(4):905-11.

5. Ota E, Haruna M, Suzuki M, Anh DD, Tho le H, Tam NT, et al. Maternal body mass index and gestational weight gain and their association with perinatal outcomes in Vietnam. Bull World Health Organ. 2011;89(2):127-36.

6. Wong W, Tang NL, Lau TK, Wong TW. A new recommendation for maternal weight gain in Chinese women. J Am Diet Assoc. 2000;100(7):791-6.

7. Heerman WJ, Bian A, Shintani A, Barkin SL. The interaction between maternal pre-pregnancy bmi and gestational weight gain shapes infant growth. Acad Pediatr. 2014;14(5): 463-70.

8. Thorsdottir I, Torfadottir JE, Birgisdottir BE, Geirsson RT. Weight gain in women of normal weight before pregnancy: complications in pregnancy or delivery and birth outcome. Obstetrics and Gynecology. 2002;99(5.1):799-806.

9. Brennand EA, Dannenbaum D, Willows ND. Pregnancy outcomes of first Nations women in relation to pregravid weight and pregnancy weight gain. Journal of Obstetrics and Gynaecology Canada. 2005;27(10):936-44.

10. Kieffer EC, Tabaei BP, Carman WJ, Nolan GH, Guzman JR, Herman WH. The influence of maternal weight and glucose tolerance on infant birth weight in Latino mother-infant pairs. American Journal of Public Health. 2006;96(12):2201-8.

11. Li N, Liu E, Guo J, Pan L, Li B, Wang P, et al. Maternal prepregnancy body mass index and gestational weight gain on pregnancy outcomes.
PLoS ONE. 2013;8(12):e82310.

12. Chasan-Taber L, Silveira M, Waring ME, Pekow P, Braun B, Manson JAE, et al. Gestational weight gain, body mass index, and risk of hypertensive disorders of pregnancy in a predominantly Puerto Rican population. Matern Child Health J. 2016;20 (9):1804-13.

13. Li N, Liu E, Guo J, Pan L, Li B, Wang P, et al. Maternal prepregnancy body mass index and gestational weight gain on pregnancy outcomes. PLoS ONE. 2013;8(12):e82310.

14. Bush RA, Connelly CD, Farquharson HR, Johnson M, Estrada J, Tardiel K, et al. Maternal characteristics \& gestational weight gain. J Nurs Res Pract. 2018;2(3):15-20.

15. Zhu T, Tang J, Zhao F, Qu Y, Mua D. Association between maternal obesity and offspring Apgar score or cord $\mathrm{pH}$ : a systematic review and meta-analysis. Sci Rep. 2015;5:18386.

16. Calika KY, Yildizb NK, Erkayaa R. Effects of gestational weight gain and body mass index on obstetric outcome. Saudi J Bio Sci. 2018;25(6):10859.

17. Baugh N, Harris D, Aboueissa AEM, Sarton C, Lichter E. The impact of maternal obesity and excessive gestational weight gain on maternal and infant outcomes in maine: analysis of pregnancy risk assessment monitoring system results from 2000 to 2010. Journal of Pregnancy. 2016;2016:1-10.

18. Tabatabaei MSM. Gestational weight gain, prepregnancy body mass index related to pregnancy outcomes in Kazerun, Fars, Iran. J Prenat Med. 2011; 5(2):35-40.

Cite this article as: Singh K, Goel A, Narain A. Gestational weight gain and its effect on fetomaternal outcome. Int J Reprod Contracept Obstet Gynecol 2020:9:4477-81. 